\title{
Caves Biodiversity in the Marine Area of Riviera d'Ulisse Regional Park, Italy: Grotta del Maresciallo Overview
}

Adriano Madonna ${ }^{1}$, Magdy A. Alwany ${ }^{2}$, Dea Rabbito ${ }^{1}$, Samantha Trocchia ${ }^{1}$, Sofiane Labar ${ }^{3}$, Fagr Kh. Abdel-Gawad ${ }^{4}$, Rosa D'Angelo ${ }^{1}$, Alessandra Gallo ${ }^{1,5}$ Giulia Guerriero ${ }^{1,6}$, Gaetano Ciarcia ${ }^{1,6}$

${ }^{1}$ EClab, Department of Biology, University of Naples Federico II, Naples, Italy

${ }^{2}$ Dept. of Marine Science, Faculty of Science, Suez Canal University, Ismailia, Egypt

${ }^{3}$ Dept. of Biology, University of El-Tarf, REDD Lab Annaba, Algeria

${ }^{4}$ Dept. of Water Pollution Research, Centre of Excellence for Advanced Science, National Research Center (NRC), Giza, Egypt

${ }^{5}$ Stazione Zoologica "Anton Dohrn", Naples, Italy

6Interdept. Research Center for Environment (I.R.C.Env.), Federico II University, Naples, Italy

*Corresponding author: Prof. Giulia Guerriero, Dept. of Biology, Federico II University, Naples, Italy, Tel +39 0812535140 ; Fax +39 0812535154 ; E-mail: giulia.guerriero@unina.it

Received date: Apr 22, 2015; Accepted date: June 06, 2015; Published date: June 15, 2015

Copyright: (c) 2015, Guerriero G. This is an open-access article distributed under the terms of the Creative Commons Attribution License, which permits unrestricted use, distribution, and reproduction in any medium, provided the original author and source are credited.

\begin{abstract}
The caves have a significant economic importance in their role as tourist attraction and are of great importance for the presence of some rare species. The fauna identification in the "Grotta del Maresciallo" cave, situated in the Riviera di Ulisse Regional Park, started in march 2013 by a visual census and molecular approach. The studies allowed to detect 12 classes, 46 families, 47 species with their ecological niches, and the percentage contribution of each group to the Mediterranean marine cave diversity. Furthermore, we report the presence of two thermophilic species, as the star coral, Astroides calycularis (Pallas, 1766) and the goldblotch grouper, Epinephelus costae (Steindachner, 1878); the tropical species, the ringneck blenny Parablennius pilicornis (Cuvier, 1829); the endangered species, the dusky grouper Epinephelus marginatus (Lowe, 1834) included in the IUCN Red List; the rare species, the black brotula Grammonus ater (Risso, 1810), and some uncommon species such as the golden coral shrimp, Stenopus spinosus (Risso, 1826) and the spotted bumblebee shrimp, Gnatophillum elegans (Risso, 1816). Species of economic and medical interest were also recorded. In a DNA barcoding approach, Neighbour Joining (NJ) phylogenetic tree of 25 mitochondrial cytochrome oxidase subunit I species sequences, indicates that $\mathrm{COI}$ gene is suitable for an unambiguous identification. This first geological and biological attempt at the Marine Area of the "Grotta del Maresciallo" provides useful indications to focus future investigations, and may become a potential management tool for local administrations to protect these habitats.
\end{abstract}

Keywords: Grotta del Maresciallo cave, Marine areas; Preservation; Visual census; COI barcodes; Marine drug; Epinephelus marginatus

\section{Introduction}

The marine areas in a Park are geographically individuated and defined, legally protected due to their environmental, cultural and economic value [1]. In presence of natural monuments, such as caves inside the Park, the use or the public entrance in such areas are regulated by the Park plan, which provides limitations and constraints, to protect the particular sensible habitats and most vulnerable species [2]. The cave system, in fact, could be highly affected by external pollutants, such as ballast water, bilge water, wastewater discharges, and by hydrocarbons and poisonous substances present in antifouling paints, used to treat the hulls of the ships, or by the global warming [2-4]. Still there can be a biological pollution also, due to new thermophilic and/or tropical species [5-7]. For these reasons a continuous monitoring action is necessary to provide information about the costal structure, sea level changes, spatio-temporal species in the caves performed by a census made and supported by professional divers and molecular techniques [8-12]. In this optic the census and the identification represent an important step to establish the abundance/rarity degree of the marinea species $[13,14]$, as well to detect possibly cryptic species and even to describe new species [15-17]. The newest EU political actions regarding maritime strategic objectives, such as the Marine Strategy Framework Directive (MSFD), and the European Strategy for Marine and Maritime Research [18], represent a push to draw up an inventory of the alien species in the Mediterranean sea. The biodiversity and community structure in the north-western and central Mediterranean caves have been widely studied, while still few information are available for the 738 marine caves in the eastern Mediterranean [7,19,20]. However, the marine cave biodiversity list was also checked for the presence of alien species [12] in relation to their worst effect [21]. As reported in the inventory by Darling and Blum [22], organism morphology for micro- and meio-fauna can require the expertise of multiple taxonomists for complex communities, thus significantly elevating costs. In addition, depending on the taxa under investigation, availability of taxonomic expertise may be limited or altogether absent $[23,24]$. Typically, such considerations force researchers to base biodiversity estimates on identifications to family level or to "morphospecies". Furthermore, the accuracy of morphological identification is severely attenuated by the requirements of invasive species monitoring: the difficulty of identifying early life history stages (eggs and larvae) by morphological criteria is well known, and yet recognition of these stages is crucially important to the task of tracking invasions [25]. To help non-experts 
Citation: Madonna A, Alwany MA, Rabbito D, Trocchia S, Labar S, et al. (2015) Caves Biodiversity in the Marine Area of Riviera d'Ulisse Regional Park, Italy: Grotta del Maresciallo Overview. J Biodivers Endanger Species 3: $153 . \quad$ doi: $10.4172 / 2332-2543.1000153$

Page 2 of 13

in the identification process, developing a unifying identification system for animal species, an universal marker called "DNA barcode" has been used in the last decade [26,27]. This DNA barcode is the sequence of the "Folmer fragment" [28], a polymorphic part of the mitochondrial Cytochrome Oxidase subunit I gene (COI), which can be used to identify closely related species as well as higher taxa in many animal phyla. Additional studies have shown that genetic identification by "COI barcodes" can provide a useful tool to detect possibly cryptic species, to describe new species and to discuss evolutionary implications [15]. The "Grotta del Maresciallo" cave, even if it's less famous than the neighboring ones (such as the "Grotta del Turco"), presents a high variety of species, that's why the objectives of this study have been to describe relative spatial patterns of quantitative distribution and relative abundance of species; to calculate the percentage contribution of a single group to the total Mediterranean marine cave diversity, to verify the possibility to identify species by using barcoding as complementary taxonomy. This census, will serve as baseline data for future comparisons.
2013 in the Marine Area of Riviera di Ulisse caves (central Italy, LT Italy; Figure 1). The regional Park Riviera di Ulisse has been established by the Lazio Region with the law no. 2 of February 6, 2003 as an instrumental entity with the task of manage three regional protected areas, included in the cities of Minturno, Formia, Gaeta and Sperlonga: the Gianola Park and Mountain of Scauri, the natural monument 'Promontorio Villa di Tiberio and Costa Torre CapoventoPunta Cetarola', and the Regional Urban Park of Monte Orlando. By applying zonation parameters [29], the marine protected area of Monte Orlando was separated in four sectors: the Piloni, the Cigliatina, the Franata at the "Montagna Spaccata". The "Grotta del Maresciallo" cave (lat. $41^{\circ} 12^{\prime} 17^{\prime \prime} \mathrm{N}$; lon. $13^{\circ} 34^{\prime} 17^{\prime \prime} \mathrm{E}$ ), placed close to the cliff of the Montagna Spaccata, is a linear cave, hidden in the rock and parallel to the Grotta del Turco cave. The entrance of the cave is visible on the surface as a thin creek which, going under and straight to the bottom, widen in a large chamber (Figure 1a-c).

\section{Material and Methods}

\section{Study area}

Marine area of Riviera di Ulisse Regional Park and the "Grotta del Maresciallo" cave: Underwater surveys were carried out from March

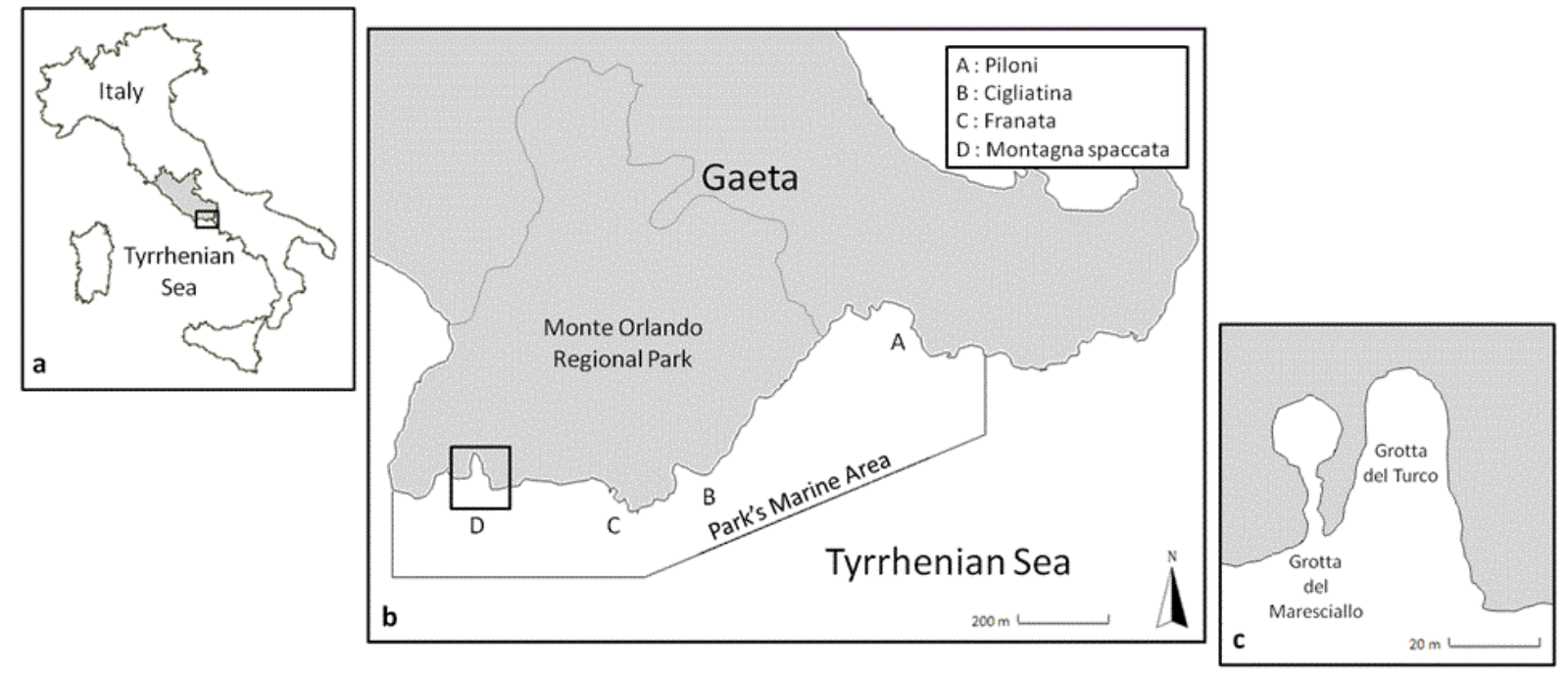

Figure 1: Geographical framework of the Marine Area of Riviera di Ulisse Regional Park, at the Latium Italian Region (a); its areas in the Tyrrhenian Sea (b); site of caves: Grotta del Maresciallo and Grotta del Turco (c).

\section{Field studies}

Cave exploration: The investigated cave was blind or with several openings and varied remarkably in terms of morphology and length, presence/absence of the ceiling and characteristics of the bottom (e.g. rocky vs muddy); data were reported by specialized cave diving techniques before census and sampling.

Census and Sampling: A detailed survey of the distribution and abundance of species in a range of habitats and locations using visual census techniques was done. The followed morphological classification was in agreement with that proposed in Systema Porifera [30], the World Porifera Database, WPD [31], the World Register of Marine
Species, WoRMS [32] and the Integrated Taxonomic Information System (http://www.itis.gov) and in numerous and specific text and manuscripts Table 1 e.g. for Bryozoan, Chimenz Gusso et al., [33].

Data analyses: Analysis of biodiversity index was used to assess quantitative distribution and relative abundance of species. Species richness was expressed by considering the number of species (D), and species diversity, but homogeneity were determined using the Shannon-Wiener (SW) diversity index $\left(\mathrm{H}^{\prime}\right)$ and the Evenness index $\left(\mathrm{J}^{\prime}\right)$ [34]. The presence of Porifera, Cnidaria and Bryozoa was reported in square meters $(0.5$ to $3 \mathrm{mq})$, and the colonies counted as single individuals (see Table 1, relative abundance) following Loya [35]. 
Citation: Madonna A, Alwany MA, Rabbito D, Trocchia S, Labar S, et al. (2015) Caves Biodiversity in the Marine Area of Riviera d'Ulisse

Regional Park, Italy: Grotta del Maresciallo Overview. J Biodivers Endanger Species 3: $153 . \quad$ doi: 10.4172/2332-2543.1000153

Page 3 of 13

These parameters were calculated for each site (outside and inside the cave) by pooling data from the sample replicates. The percentage contribution of each group to the total Mediterranean marine cave diversity was calculated following Gerovasileiou \& Voultsiadou [36].

\section{Molecular identification}

Sampling and DNA Extraction: In order to examine the resolution power of the molecular markers in species delineation and to account for intraspecific sequence variation, avoiding any misleading results, DNA barcoding studies in samples (100mg of each specie) whose COI sequence of which is already reported sequence in GenBank (see Table 1) were performed thanks to SCUBA divers specimens collection through non-destructive methods. For the species belonging to the Actinopterygii family (Pisces) the DNA extraction was performed as reported in Di Finizio et al., [37] with a phenol/chloroform standard method by using autoclaved glassware and equipment. About $100 \mathrm{mg}$ of ground freeze dried tissues were mixed in a DNA extraction buffer $(50 \mathrm{mM} \mathrm{NaCl}, 10 \mathrm{mM}$ EDTA and $10 \mathrm{mM}$ Tris base) and the cells were lysed by adding $2 \%$ sodium dodecyl sulfate. The RNA was removed by adding RNAse $(10 \mathrm{mg} / \mathrm{mL})$ followed by incubation at $37^{\circ} \mathrm{C}$ for $30 \mathrm{~min}$. Proteinase $\mathrm{K}$ was added $(0,5 \mathrm{mg} / \mathrm{mL})$ to remove protein and the samples were incubated for $1 \mathrm{~h} 37^{\circ} \mathrm{C}$ in a shaking water bath. The extracts were further purified by extracting twice with phenol:chloroform:isoamyl alcohol $(25: 24: 1 \mathrm{v} / \mathrm{v})$ and by centrifuging at $10,000 \times \mathrm{g}$ for $15 \mathrm{~min}$ at $4^{\circ} \mathrm{C}$. The upper aqueous layer was transferred into a new micro-centrifuge tube and the DNA was precipitate by adding 1/10th volume of $3 \mathrm{M}$ sodium acetate at $\mathrm{pH} 5.2$ and two volumes of $100 \%$ chilled ethanol to each sample and mixed centrifuged at $15,000 \times \mathrm{g}$ for $30 \mathrm{~min}$ at $4^{\circ} \mathrm{C}$. The pellet was washed with $70 \%$ ethanol, air dried, and finally re-suspended in $50 \mu \mathrm{l}$ sterilized deionized water. Optical density (OD) of each sample was measured at 260 and $280 \mathrm{~nm}$ respectively, by UV-spectrophotometer (Biochrom Libra S12), and the purity of DNA was measured by the OD260/ OD280 ratio (ideal ratio $=1.7-2.0$ ), and the quality by electrophoresis on a $0.8 \%$ agarose gel and visualized under UV light [37].

Total DNA of samples belonging to all other taxa was extracted using Qiagen DNeasy mini kits according to the manufacturer's instructions. For the initial tissue homogenization, a cube of tissue approximately $3 \mathrm{~mm} 3$ in size was ground. After initial digestion a centrifugation step was added e.g. to remove spicules, in case of sponges, prior to using the lilac Qiashredder Mini Spin column.

DNA Barcoding: DNA Barcoding Sequences of 25 species were obtained to compare the applicability of the COI genes as markers for DNA barcoding. PCR amplification was performed as previously published [37] using the following primers: COI_UP (5'ACTTCAGGGTGACCGAAGAATCAGAA-3') and COI_DW (5'ATCTTTGGTGCATGAGCAGGAATAGT-3') [38] for the species belonging to the Actinopterygii family. For all other species standard primers [28] were used. PCR reaction was performed in a Techgene Thermal Cycler (Thecne Ltd., Cambridge, UK). Thirty-five cycles of amplification were carried out in a reaction buffer containing $50 \mathrm{mM}$ $\mathrm{KCl}, 10 \mathrm{mM}$ Tris/HCl, pH 9.0; $10 \mathrm{mM} \mathrm{NaCl} ; 0.01 \mathrm{mM}$ EDTA; $2.5 \mathrm{mM}$ of each dNTP; $1 \mu \mathrm{M}$ of each primer; $10 \mathrm{ng}$ of template DNA; 0.5 unit of Taq DNA polymerase (Invitrogen, Milan, Italy). PCR amplification for COI Actinopterygii species conditions were as follows: denaturation for 50 seconds at $94^{\circ} \mathrm{C}$; annealing for 50 seconds at $54^{\circ} \mathrm{C}$, and extension for 1 minute at $72^{\circ} \mathrm{C}$; while for other species amplification condition were: denaturation for 1 minute at $95^{\circ} \mathrm{C}$; annealing for 1 minute at $40^{\circ} \mathrm{C}$, and extension for 1 and a half minutes at $72^{\circ} \mathrm{C}$, followed by a final extension step at $72^{\circ} \mathrm{C}$ for seven minutes. At the end of the incubation $5 \mu$ l of PCR products were separated by electrophoresis through $2 \%$ agarose gel and visualized under UV light. A 100 bp ladder (Invitrogen, Milan, Italy) was used to estimate the fragment size of the amplicons generated. Amplified DNA was desalted with Microcon 100 spin columns (Millipore-Amicon, Belford, MA, USA) according to the manufacturer's instructions and sequenced using Big Dye TM Terminator Cycle Sequencing Chemistry (Applied Biosystems, Foster City, CA, USA) in an automatic capillarity sequencer (ABI 310 Genetic Analizer; Applied Biosystems).

Multiple alignments of these orthologous sequences were performed with the programme Clustal $\mathrm{W}$ [39] as implemented in BioEdit (version 7.0.4.1), [40] to ensure that all sequences of COI marker gene provide a homologous fragment. COI sequences were translated into amino acids with the online program ExPASy translation tool (http://web.expasy.org/translate/) in order to exclude sequencing errors and to avoid the inclusion of pseudogene sequences in the datasets. Neighbour Joining (NJ) trees were constructed and genetic distance was calculated within species [41]. Since the aim of this task was to identify species using barcodes, phylogenetic trees were constructed without selecting a priori an evolutionary model appropriate for the dataset.

\section{Results}

\section{General description of study area}

The "Grotta del Maresciallo" cave is a completely submerged tunnel, 32 meters long and 2.5 meters wide, and culminates in a circular chamber completely dark, with little stalactites and stalagmites, which can form only in air (data not shown). The water depth varies depending on the state of erosion of the sediment: typically is around 7 meters, however, is reduced in the vicinity of the chamber, which features on the bottom sediment and rock bass. Light and hydro-dynamism are reported in Figure 2 and in Table 1 in relation to the important parameters that affect the biocenosis of the cave.

General distribution, abundance of species and taxa Mediterranean biodiversity percentage: Common name of fish species in the entrance and inside the "Grotta del Maresciallo", their distribution as the site physical conditions detected are reported in Tab.1. Furthermore, the morphological reference and GenBank accession number of species barcode sequences, informative for discrimination, scientific name and taxonomy of the Grotta del Maresciallo fauna are also included. The total number of species detected is 47 ; they belong to 46 families and 12 different classes. Abundance and richness of species change from the semidark zone, zone 1 , to the completely dark one, zone 2 (Table 2 ). The determinations show that in zone 1 there is an intermediate situation regarding the species richness; a fair distribution of individuals in the community is valuable, thus not one species is dominant compared to the others; even if the biodiversity is low there is a wide variety of species in relation to the small size of the area considered. 
Citation: Madonna A, Alwany MA, Rabbito D, Trocchia S, Labar S, et al. (2015) Caves Biodiversity in the Marine Area of Riviera d'Ulisse Regional Park, Italy: Grotta del Maresciallo Overview. J Biodivers Endanger Species 3: $153 . \quad$ doi: $10.4172 / 2332-2543.1000153$

\section{Rock cover percentage}

0

$100 \%$
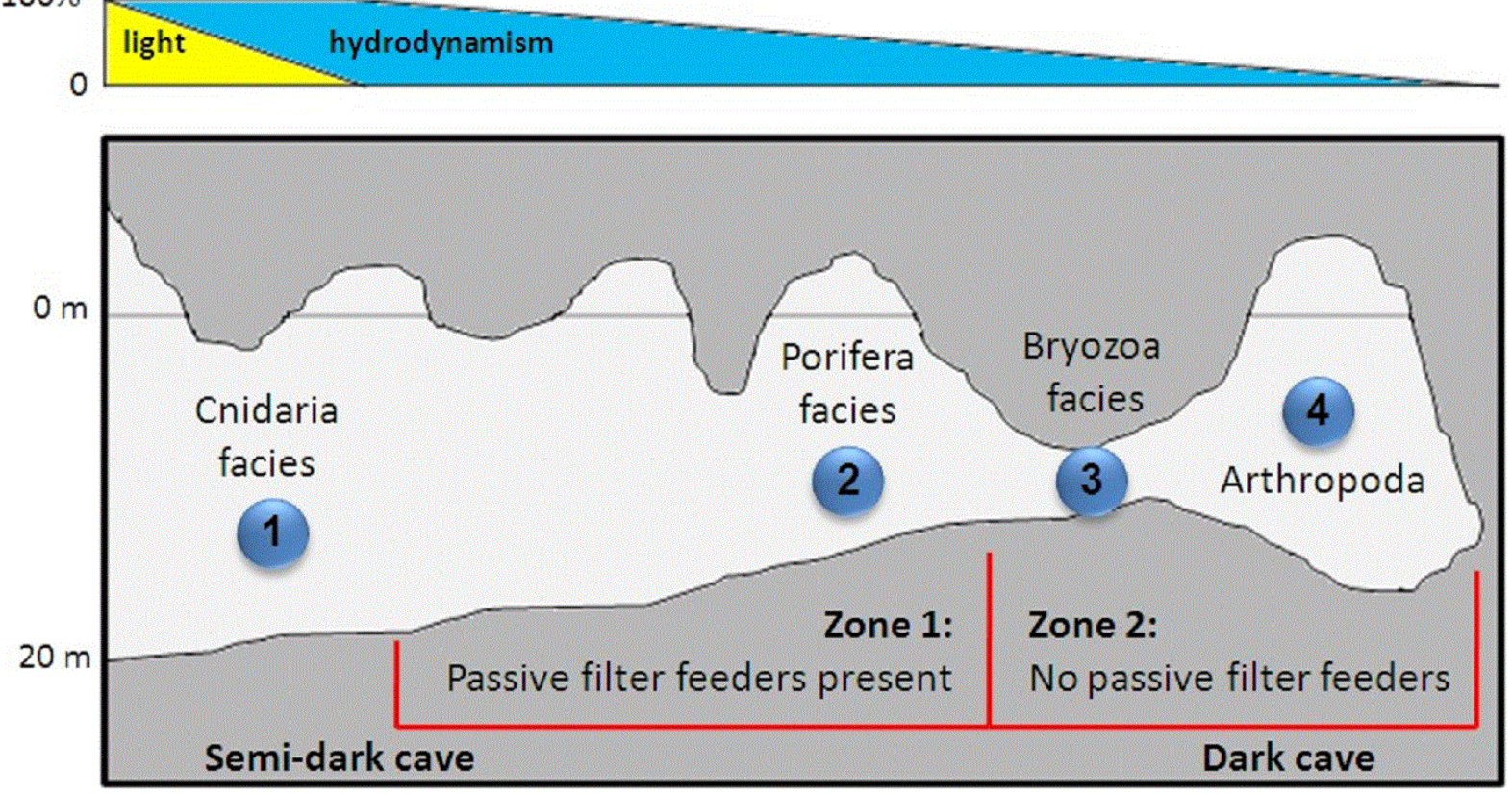

Figure 2: Drawing of "Grotta del Maresciallo": two parameters, light and hydro-dynamism affecting the biocenosis of the cave (zone 1 and 2). In green is evidenced the rock cover, which is maximum in the zone 1, composed mainly of sessile organisms. The light, such as the hydrodynamism, are maximum at the zone 1 , to completely disappear in zone 2 . Schematic indication of fauna detected.

\begin{tabular}{|c|c|c|c|c|c|c|c|c|}
\hline Location & Luminosity & $\begin{array}{l}\text { Species Common } \\
\text { Name }\end{array}$ & R.a. & $\begin{array}{l}\text { Number of } \\
\text { Specimens } \\
\text { Detected }\end{array}$ & $\begin{array}{l}\text { Taxonomical } \\
\text { Reference }\end{array}$ & $\begin{array}{l}\text { COI } \\
\text { GenBank } \\
\text { Accession } \\
\text { Number }\end{array}$ & Identified Species & $\begin{array}{l}\text { Specie Taxonomy } \\
\text { (Phylum, Subphylum, } \\
\text { Class, Order, Family) }\end{array}$ \\
\hline \multirow{5}{*}{$\begin{array}{l}\text { Grotta del } \\
\text { Maresciallo } \\
\text { zone 1 (a) }\end{array}$} & d & $\begin{array}{l}\text { Bluish encrusting } \\
\text { sponge }\end{array}$ & $\mathrm{h}$ & $1(2 \mathrm{mq})$ & Cerrano, 2004 & n.d. & $\begin{array}{l}\text { Phorbas tenacior } \\
\text { (Topsent, 1925) }\end{array}$ & $\begin{array}{l}\text { Porifera,Cellularia, } \\
\text { Demospongiae, } \\
\text { Poecilosclerida, } \\
\text { Hymedesmiidae }\end{array}$ \\
\hline & d & $\begin{array}{ll}\text { Yellow } & \text { network } \\
\text { sponge } & \end{array}$ & $\mathrm{h}$ & 15 & Hooper, 2002 & n.d. & $\begin{array}{l}\text { Clathrina clathrus } \\
\text { (Schmidt, 1864) }\end{array}$ & $\begin{array}{l}\text { Porifera, Celluaria, } \\
\text { Calcarea, Clathrinida, } \\
\text { Clathrinidae }\end{array}$ \\
\hline & d & $\begin{array}{ll}\begin{array}{l}\text { Orange } \\
\text { sponge }\end{array} & \text { lumpy } \\
\end{array}$ & $\mathrm{h}$ & 5 & Díaz, 2015 & HQ379408 & $\begin{array}{l}\text { Acanthella acuta } \\
\text { (Schmidt, 1862) }\end{array}$ & $\begin{array}{l}\text { Porifera, Celluaria, } \\
\text { Demospongiae, } \\
\text { Halichondrida, } \\
\text { Dictyonellidae }\end{array}$ \\
\hline & d & $\begin{array}{l}\text { Orange } \\
\text { sponge }\end{array}$ & $\mathrm{h}$ & 5 & Cerrano, 2004 & JX999060 & $\begin{array}{l}\text { Agelas oroides } \\
\text { (Schmidt, 1864) }\end{array}$ & $\begin{array}{l}\text { Porifera, Celluaria, } \\
\text { Demospongiae, } \\
\text { Agelasida, Agelasidae }\end{array}$ \\
\hline & d & $\begin{array}{l}\text { Orange-red } \\
\text { encrusting sponge }\end{array}$ & $\mathrm{h}$ & 7 & Mojetta, 2003 & JX999091 & $\begin{array}{l}\text { Cramber crambe } \\
\text { (Schmidt, 1862) }\end{array}$ & $\begin{array}{l}\text { Porifera, Celluaria, } \\
\text { Demospongiae, } \\
\text { Poecilosclerida, } \\
\text { Crambeidae }\end{array}$ \\
\hline
\end{tabular}


Citation: Madonna A, Alwany MA, Rabbito D, Trocchia S, Labar S, et al. (2015) Caves Biodiversity in the Marine Area of Riviera d'Ulisse Regional Park, Italy: Grotta del Maresciallo Overview. J Biodivers Endanger Species 3: $153 . \quad$ doi: $10.4172 / 2332-2543.1000153$

Page 5 of 13

\begin{tabular}{|c|c|c|c|c|c|c|c|}
\hline$d$ & $\begin{array}{l}\text { Kidney-shaped } \\
\text { sponge }\end{array}$ & $\mathrm{h}$ & 25 & Cerrano, 2004 & JX999074 & $\begin{array}{l}\text { Chondrosia reniformis } \\
\text { (Nardo, 1847) }\end{array}$ & $\begin{array}{l}\text { Porifera, Celluaria, } \\
\text { Demospongiae, } \\
\text { Chondrosida, } \\
\text { Chondrillidae }\end{array}$ \\
\hline$d$ & Stony sponge & $\mathrm{h}$ & $1(3 \mathrm{mq})$ & Cerrano, 2004 & JX999088 & $\begin{array}{l}\text { Petrosia ficiformis } \\
\text { (Poiret, 1789) }\end{array}$ & $\begin{array}{l}\text { Porifera, Celluaria, } \\
\text { Demospongiae, } \\
\text { Haplosclerida, } \\
\text { Petrosiidae }\end{array}$ \\
\hline$d$ & $\begin{array}{l}\text { Encrusting orange } \\
\text { sponge }\end{array}$ & $\mathrm{h}$ & 20 & Mojetta, 2003 & n.d. & $\begin{array}{l}\text { Spirastrella cunctatrix } \\
\text { (Schmidt, 1868) }\end{array}$ & $\begin{array}{l}\text { Porifera, Celluaria, } \\
\text { Demospongiae, } \\
\text { Hadromerida, } \\
\text { Spirastrellidae }\end{array}$ \\
\hline$d$ & Bath Sponge & $\mathrm{h}$ & 15 & Cerrano, 2004 & HQ830364 & $\begin{array}{l}\text { Spongia officinalis } \\
\text { (Linnaeus, 1759) }\end{array}$ & $\begin{array}{l}\text { Porifera, Celluaria, } \\
\text { Demospongiae, } \\
\text { Dictyoceratida, } \\
\text { Spongiidae }\end{array}$ \\
\hline$d$ & Carnaccia & $\mathrm{h}$ & 20 & Mojetta, 2003 & JQ082796 & $\begin{array}{l}\text { Scalarispongia } \\
\text { scalaris (Schmidt, } \\
1862)\end{array}$ & $\begin{array}{l}\text { Porifera, Celluaria, } \\
\text { Demospongiae, } \\
\text { Dictyoceratida, } \\
\text { Thorectidae }\end{array}$ \\
\hline$d$ & Star Coral & 1 & $1(1 \mathrm{mq})$ & Trainito, 2004 & JQ343192 & $\begin{array}{l}\text { Astroides calycularis } \\
\text { (Pallas, 1766) }\end{array}$ & $\begin{array}{l}\text { Cnidaria, Anthozoaria, } \\
\text { Anthozoa, Scleractinia, } \\
\text { Dendrophylliidae }\end{array}$ \\
\hline$d$ & $\begin{array}{l}\text { Yellow encrusting } \\
\text { anemone }\end{array}$ & $\mathrm{m}$ & $1(2 \mathrm{mq})$ & Trainito, 2004 & EF672659 & $\begin{array}{l}\text { Parazoanthus } \\
\text { axinellae (Schmidt, } \\
1862)\end{array}$ & $\begin{array}{l}\text { Cnidaria, Anthozoaria, } \\
\text { Anthozoa, Zoantharia, } \\
\text { Parazoanthidae }\end{array}$ \\
\hline$d$ & False coral & $\mathrm{h}$ & $1(2 \mathrm{mq})$ & Chimenz, 2004 & n.d. & $\begin{array}{l}\text { Myriapora truncata } \\
\text { ( Pallas, 1766) }\end{array}$ & $\begin{array}{l}\text { Bryozoa, } \\
\text { Gymnolaemata, } \\
\text { Cheilostomatida, } \\
\text { Myriozoidae }\end{array}$ \\
\hline$d$ & Ross coral & $\mathrm{m}$ & $1(0,5 m)$ & Chimenz, 2004 & n.d. & $\begin{array}{l}\text { Pentapora fascialis } \\
\text { ( Pallas, 1766) }\end{array}$ & $\begin{array}{l}\text { Bryozoa, } \\
\text { Gymnolaemata, } \\
\text { Cheilostomatida, } \\
\text { Bitectiporidae }\end{array}$ \\
\hline$d$ & Neptune's lace & $\mathrm{m}$ & 10 & Chimenz, 2004 & FJ196084 & $\begin{array}{l}\text { Reteporella grimaldii } \\
\text { (Jullien, 1903) }\end{array}$ & $\begin{array}{l}\text { Bryozoa, } \\
\text { Gymnolaemata, } \\
\text { Cheilostomatida, } \\
\text { Phidoloporidae }\end{array}$ \\
\hline$d-t . d$ & Leopard sea slug & $a$ & 15 & Trainito, 2005 & AF120637 & $\begin{array}{l}\text { Discodoris } \\
\text { atromaculata (Bergh, } \\
1880)\end{array}$ & $\begin{array}{l}\text { Mollusca, Conchifera, } \\
\text { Gastropoda, } \\
\text { Nudibranchia, } \\
\text { Discodoridinae }\end{array}$ \\
\hline$d-t . d$ & Giant doris & I & 5 & Trainito, 2005 & LN715204 & $\begin{array}{l}\text { Felimare picta } \\
\text { (Schultz in Philippi, } \\
\text { 1836) }\end{array}$ & $\begin{array}{l}\text { Mollusca, Conchifera, } \\
\text { Gastropoda, } \\
\text { Nudibranchia, } \\
\text { Chromodorididae }\end{array}$ \\
\hline$d-t . d$ & $\begin{array}{l}\text { Mediterranean } \\
\text { violet aeolid }\end{array}$ & $a$ & 5 & Trainito, 2005 & HQ616753 & $\begin{array}{l}\text { Flabellina affinis } \\
\text { (Gmelin, 1791) }\end{array}$ & $\begin{array}{l}\text { Mollusca, Conchifera, } \\
\text { Gastropoda, } \\
\text { Nudibranchia, } \\
\text { Flabellinidae }\end{array}$ \\
\hline$d-t . d$ & $\begin{array}{l}\text { Red-mounthed rock } \\
\text { shell }\end{array}$ & $\mathrm{m}$ & 25 & Gofas, 2001 & FR695839 & $\begin{array}{l}\text { Stramonita } \\
\text { haemastoma } \\
\text { (Linnaeus, 1767) }\end{array}$ & $\begin{array}{l}\text { Mollusca, Conchifera, } \\
\text { Gastropoda, } \\
\text { Neogastropoda, } \\
\text { Muricidae }\end{array}$ \\
\hline$d-t . d$ & Lurid cowry & I & 5 & Repetto, 2005 & AY161695 & $\begin{array}{l}\text { Luria lurida } \\
\text { (Linnaeus, 1758) }\end{array}$ & $\begin{array}{l}\text { Mollusca, Conchifera, } \\
\text { Gastropoda, } \\
\text { Littiorinimorpha, } \\
\text { Cypraeidae }\end{array}$ \\
\hline
\end{tabular}


Citation: Madonna A, Alwany MA, Rabbito D, Trocchia S, Labar S, et al. (2015) Caves Biodiversity in the Marine Area of Riviera d'Ulisse Regional Park, Italy: Grotta del Maresciallo Overview. J Biodivers Endanger Species 3: $153 . \quad$ doi: $10.4172 / 2332-2543.1000153$

Page 6 of 13

\begin{tabular}{|c|c|c|c|c|c|c|c|c|}
\hline & d & Noah ark shell & $\mathrm{h}$ & 50 & Doneddu, 2005 & n.d. & $\begin{array}{l}\text { Arca noae (Linnaeus, } \\
1758 \text { ) }\end{array}$ & $\begin{array}{l}\text { Mollusca, } \\
\text { Bivalvia, } \\
\text { Arcidae }\end{array}$ \\
\hline & $d-t . d$ & Broad lobster & 1 & 20 & Trainito, 2004 & KC789473 & $\begin{array}{l}\text { Scyllarus arctus } \\
\text { (Linnaeus, 1758) }\end{array}$ & $\begin{array}{l}\text { Arthropoda, Crustacea, } \\
\text { Malacostraca, } \\
\text { Decapoda, Scyllaridae }\end{array}$ \\
\hline & $d$ & Red starfish & $\mathrm{h}$ & 10 & Trainito, 2004 & GU330217 & $\begin{array}{l}\text { Echinaster sepositus } \\
\text { (Retzius, 1783) }\end{array}$ & $\begin{array}{l}\text { Echinodermata, } \\
\text { Eleutherozoa, } \\
\text { Asteroidea, } \\
\text { Spinulosida, } \\
\text { Echinasteridae }\end{array}$ \\
\hline & $\mathrm{d}$ & Purple seastar & $\mathrm{h}$ & 10 & Mojetta, 2003 & n.d. & $\begin{array}{l}\text { Ophidiaster } \\
\text { ophidianus (Lamarck, } \\
1816 \text { ) }\end{array}$ & $\begin{array}{l}\text { Echinodermata, } \\
\text { Eleutherozoa, } \\
\text { Asteroidea, Valvatida, } \\
\text { Ophidiasteridae }\end{array}$ \\
\hline & $d$ & Spiny starfish & $\mathrm{h}$ & 7 & Hansson, 2001 & n.d. & $\begin{array}{l}\text { Marthasterias } \\
\text { glacialis (Linnaeus, } \\
1758)\end{array}$ & $\begin{array}{l}\text { Echinodermata, } \\
\text { Eleutherozoa, } \\
\text { Asteroidea, } \\
\text { Forcipulatida, } \\
\text { Asteriidae }\end{array}$ \\
\hline & $d$ & Brown brittle star & $\mathrm{h}$ & 5 & Stöhr, 2009 & n.d. & $\begin{array}{l}\text { Ophioderma } \\
\text { longicauda } \\
\text { (Bruzelius, 1805) }\end{array}$ & $\begin{array}{l}\text { Echinodermata, } \\
\text { Eleutherozoa, } \\
\text { Ophiuroidea, } \\
\text { Ophiurida, } \\
\text { Ophiodermatidae }\end{array}$ \\
\hline & $d$ & Feather star & $\mathrm{h}$ & 3 & Mojetta, 2003 & KC626517 & $\begin{array}{l}\text { Antedon } \\
\text { mediterranea } \\
\text { (Lamarck, 1816) }\end{array}$ & $\begin{array}{l}\text { Echinodermata, } \\
\text { Crinozoa, Crinoidea, } \\
\text { Comatulida, } \\
\text { Antedonidae }\end{array}$ \\
\hline & $d$ & Black sea urchin & $\mathrm{h}$ & 20 & Hansson, 2001 & JQ745256 & $\begin{array}{l}\text { Arbacia lixula } \\
\text { (Linnaeus, 1758) }\end{array}$ & $\begin{array}{l}\text { Echinodermata, } \\
\text { Echinozoa, Echinoidea, } \\
\text { Arbacioida, Arbaciidae }\end{array}$ \\
\hline & $d$ & $\begin{array}{l}\text { Common sea } \\
\text { urchin }\end{array}$ & $\mathrm{h}$ & 20 & Trainito, 2004 & EF462949 & $\begin{array}{l}\text { Paracentrotus lividus } \\
\text { (Lamarck, 1816) }\end{array}$ & $\begin{array}{l}\text { Echinodermata, } \\
\text { Echinozoa, Echinoidea, } \\
\text { Camarodonta, } \\
\text { Parechinidae }\end{array}$ \\
\hline & $d$ & $\begin{array}{l}\text { Light bulb sea } \\
\text { squirt }\end{array}$ & $\mathrm{m}$ & 7 & Cerrano, 2004 & AY603104 & $\begin{array}{l}\text { Clavelina lepadiformis } \\
\text { (Müller, 1776) }\end{array}$ & $\begin{array}{l}\text { Chordata, Tunicata, } \\
\text { Ascidiacea, } \\
\text { Enterogona, } \\
\text { Clavelinidae }\end{array}$ \\
\hline & $d$ & Red sea-squirt & $\mathrm{h}$ & 10 & Cerrano, 2004 & n.d. & $\begin{array}{l}\text { Halocynthia papillosa } \\
\text { (Gunnerus, 1765) }\end{array}$ & $\begin{array}{l}\text { Chordata, Tunicata, } \\
\text { Ascidiacea, } \\
\text { Pleurogona, Pyuridae }\end{array}$ \\
\hline & $d-t . d$ & Red scorpionfish & $\mathrm{h}$ & 15 & Louisy, 2006 & KJ768308 & $\begin{array}{l}\text { Scorpaena notate } \\
\text { (Linnaeus, 1758) }\end{array}$ & $\begin{array}{l}\text { Chordata, Vertebrata, } \\
\text { Actinopterygii, } \\
\text { Scorpaeniformes, } \\
\text { Scorpaenidae }\end{array}$ \\
\hline & $d$ & Ringneck blenny & $\mathrm{m}$ & 6 & Louisy, 2006 & n.d. & $\begin{array}{l}\text { Parablennius } \\
\text { pilicornis (Cuvier, } \\
1829)\end{array}$ & $\begin{array}{l}\text { Chordata, Vertebrata, } \\
\text { Actinopterygii, } \\
\text { Perciformes, Blenniidae }\end{array}$ \\
\hline & $d$ & $\begin{array}{l}\text { Mediterranean } \\
\text { moray }\end{array}$ & $\mathrm{h}$ & 5 & Mojetta, 2003 & KJ768264 & $\begin{array}{l}\text { Muraena helena } \\
\text { (Linnaeus, 1758) }\end{array}$ & $\begin{array}{l}\text { Chordata, Vertebrata, } \\
\text { Actinopterygii, } \\
\text { Anguilliformes, } \\
\text { Muraenidae }\end{array}$ \\
\hline $\begin{array}{l}\text { Grotta del } \\
\text { Maresciallo } \\
\text { zone } 2(\mathrm{~b})\end{array}$ & t.d & Common prawn & $\mathrm{h}$ & 50 & Howson, 1997 & n.d. & $\begin{array}{l}\text { Palaemon serratus } \\
\text { (Pennant, 1777) }\end{array}$ & $\begin{array}{l}\text { Arthropoda, Crustacea, } \\
\text { Malacostraca, } \\
\text { Decapoda, } \\
\text { Palaemonidae }\end{array}$ \\
\hline
\end{tabular}


Citation: Madonna A, Alwany MA, Rabbito D, Trocchia S, Labar S, et al. (2015) Caves Biodiversity in the Marine Area of Riviera d'Ulisse Regional Park, Italy: Grotta del Maresciallo Overview. J Biodivers Endanger Species 3: $153 . \quad$ doi: $10.4172 / 2332-2543.1000153$

Page 7 of 13

\begin{tabular}{|c|c|c|c|c|c|c|c|}
\hline t.d & Narwal shrimp & $\mathrm{m}$ & 50 & Holthius, 1980 & n.d. & $\begin{array}{l}\text { Parapandalus narval } \\
\text { (Fabricius, 1787) }\end{array}$ & $\begin{array}{l}\text { Arthropoda, Crustacea, } \\
\text { Malacostraca, } \\
\text { Decapoda, } \\
\text { Pandaloidea }\end{array}$ \\
\hline t.d & $\begin{array}{l}\text { Spotted bumblebee } \\
\text { shrimp }\end{array}$ & I & 3 & Trainito, 2004 & n.d. & $\begin{array}{l}\text { Gnathophyllum } \\
\text { elegans (Risso, 1816) }\end{array}$ & $\begin{array}{l}\text { Arthropoda, Crustacea, } \\
\text { Malacostraca, } \\
\text { Decapoda, } \\
\text { Gnathophyllidae }\end{array}$ \\
\hline t.d & $\begin{array}{l}\text { Golden } \quad \text { coral } \\
\text { shrimp }\end{array}$ & I & 20 & Trainito, 2004 & n.d. & $\begin{array}{l}\text { Stenopus spinosus } \\
\text { (Risso, 1826) }\end{array}$ & $\begin{array}{l}\text { Arthropoda, Crustacea, } \\
\text { Malacostraca, } \\
\text { Decapoda, } \\
\text { Stenopodidae }\end{array}$ \\
\hline t.d & Spider crab & $\mathrm{m}$ & 10 & Türkay, 2001 & n.d. & $\begin{array}{l}\text { Herbstia condyliata } \\
\text { (Fabricius, 1787) }\end{array}$ & $\begin{array}{l}\text { Arthropoda, Crustacea, } \\
\text { Malacostraca, } \\
\text { Decapoda, Epialtidae }\end{array}$ \\
\hline t.d & Sponge crab & 1 & 4 & Peter, 2008 & n.d. & $\begin{array}{l}\text { Dromia personata } \\
\text { (Linnaeus, 1758) }\end{array}$ & $\begin{array}{l}\text { Arthropoda, Crustacea, } \\
\text { Malacostraca, } \\
\text { Decapoda, Dromiidae }\end{array}$ \\
\hline$d-t . d$ & Cardinal fish & $\mathrm{h}$ & 35 & Louisy, 2006 & n.d. & $\begin{array}{l}\text { Apogon imberbis } \\
\text { (Linnaeus, 1758) }\end{array}$ & $\begin{array}{l}\text { Chordata, Vertebrata, } \\
\text { Actinopterygii, } \\
\text { Perciformes, } \\
\text { Apogonidae }\end{array}$ \\
\hline t.d & Forkbeard & $\mathrm{m}$ & 10 & Louisy, 2006 & KJ768279 & $\begin{array}{l}\text { Phycis phycis } \\
\text { (Linnaeus, 1766) }\end{array}$ & $\begin{array}{l}\text { Chordata, Vertebrata, } \\
\text { Actinopterygii, } \\
\text { Gadiformes, Phycidae }\end{array}$ \\
\hline t.d & Black brotula & $1+$ & 3 & Louisy, 2006 & n.d. & $\begin{array}{l}\text { Grammonus } \\
\text { (Risso, 1810) }\end{array}$ & $\begin{array}{l}\text { Chordata, Vertebrata, } \\
\text { Actinopterygii, } \\
\text { Ophidiformes, } \\
\text { Bythitidae }\end{array}$ \\
\hline t.d & European conger & $\mathrm{m}$ & 3 & Louisy, 2006 & KJ709742 & $\begin{array}{l}\text { Conger conger } \\
\text { (Linnaeus, 1758) }\end{array}$ & $\begin{array}{l}\text { Chordata, Vertebrata, } \\
\text { Actinopterygii, } \\
\text { Anguilliformes, } \\
\text { Congridae }\end{array}$ \\
\hline$d-t . d$ & Brown meagre & $\mathrm{m}$ & 10 & Louisy, 2006 & n.d. & $\begin{array}{l}\text { Sciaenar umbra } \\
\text { (Linnaeus, 1758) }\end{array}$ & $\begin{array}{l}\text { Chordata, Vertebrata, } \\
\text { Actinopterygii, } \\
\text { Perciformes, } \\
\text { Sciaenidae }\end{array}$ \\
\hline$d-t . d$ & Dusky grouper & 1 & 1 & Louisy, 2006 & KC500692 & $\begin{array}{l}\text { Epinephelus } \\
\text { marginatus } \\
1834)\end{array}$ (Lowe, & $\begin{array}{l}\text { Chordata, Vertebrata, } \\
\text { Actinopterygii, } \\
\text { Perciformes, } \\
\text { Serranidae }\end{array}$ \\
\hline$d-t . d$ & Goldblotch grouper & 1 & 1 & Louisy, 2006 & JX456389 & $\begin{array}{l}\text { Epinephelus costae } \\
\text { (Steindachner, 1878) }\end{array}$ & $\begin{array}{l}\text { Chordata, Vertebrata, } \\
\text { Actinopterygii, } \\
\text { Perciformes, } \\
\text { Serranidae }\end{array}$ \\
\hline
\end{tabular}

Table 1: Site physical conditions and species with their abundance, morphological reference and GenBank accession number of their barcode sequences for species discrimination, scientific name and taxonomy of the Grotta del Maresciallo fauna. a. idrodynamisms present, clear or muddy water, depending on the conditions of the sea; b. idrodynamisms absent, water is generally clear in calm sea conditions; t.d. total darkness; d. dimness; r.a., relative abundance: h, high; $m$, medium; l, lower; n.d., not detected.

Inside the cave, zone 2, the indexes show that a slight inequality abundance of some species respect to others can be registered, that's why there is a little dominance of some species than others in the community; low values of the SW index mean that the division within the community is biased in favor of one species. The biodiversity is low as in zone 1 but there is less variety of species too due to the special conditions inside the cave, as the absence of light and recycling water, so that few species are able to adapt and survive. Furthermore the data obtained allowed to calculate the taxa percentage contribution of the "Grotta del Maresciallo" biodiversity (Figure 3). The data of "Grotta del Maresciallo" cave (shown in yellow) results to be greater for some taxa (Chordata, Echinodermata, Arthropoda) in relation to the biodiversity found in caves of the central Mediterranean sea (shown in green), and in general in all the caves of the Mediterranean. 
Citation: Madonna A, Alwany MA, Rabbito D, Trocchia S, Labar S, et al. (2015) Caves Biodiversity in the Marine Area of Riviera d'Ulisse Regional Park, Italy: Grotta del Maresciallo Overview. J Biodivers Endanger Species 3: $153 . \quad$ doi: 4172/2332-2543.1000153

Page 8 of 13

\begin{tabular}{|l|l|l|}
\hline \multicolumn{2}{|l|}{ “Grotta DEL MARESCIALLO” Biodiversity index ES } & \multicolumn{2}{l|}{} \\
\hline & zone 1 & zone 2 \\
\hline Tot. number of species S & 34 & 13 \\
\hline Tot. number of specimens N & 371 & 200 \\
\hline Shannon-Wiener index H' & 3.161 & 1.997 \\
\hline Simpson index D & 0.948 & 0.829 \\
\hline Evenness index J & 0.534 & 0.377 \\
\hline Berger-Parker d & 0.134 & 0.250 \\
\hline Maraglef Dm & 5.577 & 2.264 \\
\hline
\end{tabular}

Table 2: "Grotta del Maresciallo" (zone 1 and 2) biodiversity indexes.

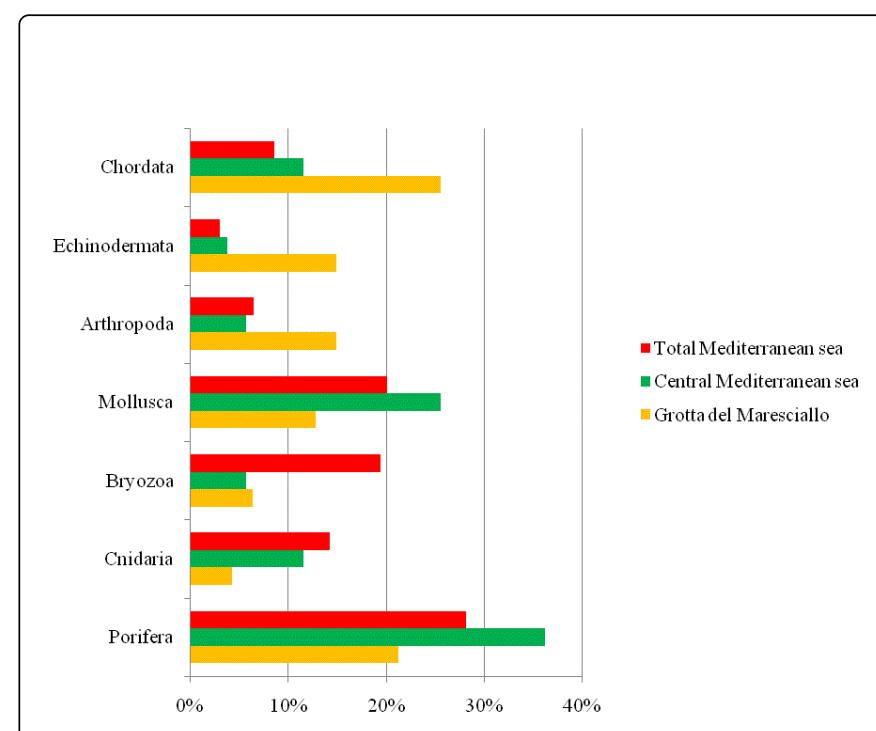

Figure 3: Contribution (\%) of marine Mediterranean cave biodiversity including data from "Grotta del Maresciallo" (modified from ref. 12).

Habitat distribution and species characteristics: Immediately before the entrance, on the left, there is a wall that descends vertically onto the bottom, filled with an abundant "sessile" fauna, such as sponges, madrepores and briozoa, organisms with a plagiotropic growth. Following Tab. 1 we can see the many species of sponges, which completely cover the bedrock, gives home to some shellfish nudibranchs, in particular the Mediterranean violet aeolid, Flabellina affinis (Gmelin, 1791) and the leopard sea slug, Discodoris atromaculata (Bergh, 1880), the latter permanently attached to the stony sponge, Petrosia ficiformis (Poiret, 1789) (Figure $4 \mathrm{c}$ ). The organisms that live at the entrance of the "Grotta del Maresciallo" cave, zone 1, have availability to a sufficient amount of food, since the sea currents carry large amounts of plankton and organic matter. Moreover, as the rate of low irradiance light decrease, there is no competition to win brighter areas, because all organisms prefer the semi-darkness. The competition is established primarily for the conquest of space on the substrate. The sponges, in particular those encrusting as Agelas oroides (Schmidt, 1864), have maximum success. They expand horizontally forming large stains. Other sponges, instead, use sessile organisms of different species as a substrate on which taking root and grow, thus becoming epibiontic organisms (e.g. Parazoanthus axinellae, Schmidt, 1862) on encrusting sponges. In this area are not observed photophilous algae, due to the low rate of light, but sciaphilous algae are present, such as red algae, including those belonging to the genus Peyssonelia and to the family of coralline known for the calcified thallus (containing calcium carbonate), and some species of green algae such as Halimeda tuna and Palmophyllum crissum, (data not shown). A few species pictures indicative of the representative taxa of the cave examined (for site location, see Tab. 1) are reported in Figure $4(\mathrm{a}-\mathrm{m})$ the orange lumpy sponge, Acanthella acuta, which colonies rocky walls at the entrance of the cave; the star coral Astroides calycularis, gathering of several individuals; the leopard sea slug, Discodoris atromaculata, lying on the stony sponge Petrosia ficiformis, the common prawn, Palaemon serratus, present in large populations on the seabed of the dark cave; the spotted bumblebee shrimp, Gnatophillum elegans, hidden among the algae; the golden coral shrimp Stenopus spinosus, placed at the bottom of the cave, in a completely dark site; the narwal shrimp, Parapandalus narval, swimming in group; the goldblotch grouper, Epinephelus costae, hidden on the seabed, between the rocks; the dusky grouper, Epinephelus marginatus, always present in the caves; the european conger, Conger conger, holed up in a crevice of the rock at the entrance of the chamber; the brown meagre, Sciaena umbra, cavedwelling and solitary species; the black brotula, Grammonus ater, a rare species living in the darkest part of the cave. For about a third of its length, the cave makes a curve that leads to a circular chamber, zone 2, where there is total darkness. The water here form a kind of 'pond', while on the right wall, some faint ray of light penetrates through two slits communicating with the outside, which also make the air breathable. The bottom of the cave consists of sediment and rocks. Among them, some croakers and musdee hide, fish that are known to live in dark environment. There are also plenty of shrimp, including the very common bait shrimp, Palaemon serratus (Pennant, 1777), shrimp saw Parapandalus narval (Fabricius, 1787) and coral shrimp, Stenopus spinosus (Risso, 1826). A higher number of species was usually associated to cave walls compared to ceilings or bottoms. The complete darkness in the innermost cave portions host the strictly cave-dwelling fish, Grammonus ater (Risso, 1810) rare and typically benthic species. 
Citation: Madonna A, Alwany MA, Rabbito D, Trocchia S, Labar S, et al. (2015) Caves Biodiversity in the Marine Area of Riviera d'Ulisse Regional Park, Italy: Grotta del Maresciallo Overview. J Biodivers Endanger Species 3: $153 . \quad$ doi: $10.4172 / 2332-2543.1000153$
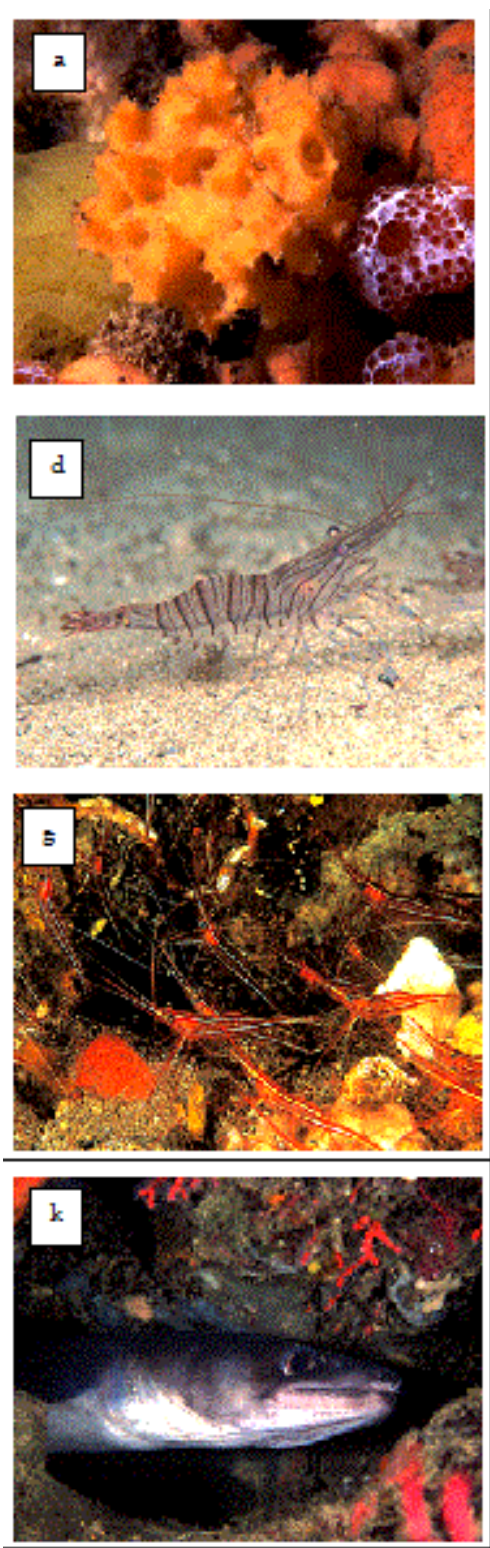
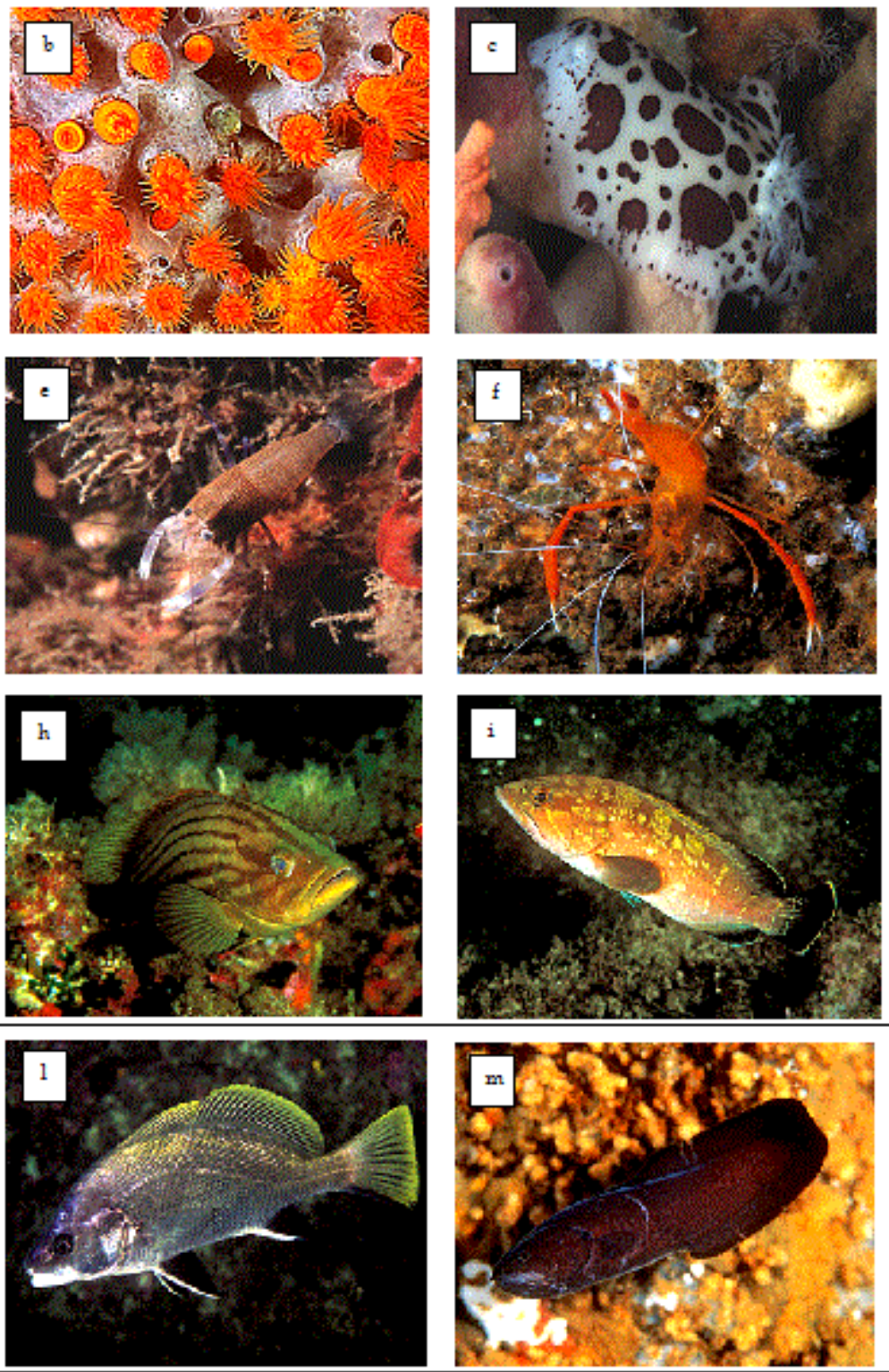

Figure 4: The main species in the "Grotta del Maresciallo". a) Acanthella acuta; b) Astroides calycularis, c) Discodoris atromaculata; d) Palaemon serratus; e) Gnatophillum elegans; f) Stenopus spinosus; g) Parapandalus narval; h) Epinephelus costae; i) Epinephelus marginatus; k) Conger conger, l) Sciaena umbra; m) Grammonus ater.

A total of 25 species collected were analyzed, thus a corresponding set of COI (532-659bp) sequences was obtained, and confirm the sequences reported in Tab. 1, available at the GenBank data base (www.ncbi.nlm.nih.gov/genbank/). No stop codons, insertions, and deletions were observed in the mitochondrial cytochrome oxidase subunit I (COI) gene of species from the "Grotta del Maresciallo" cave, indicating that they represent fragments of functional mitochondrial genes and not nuclear mitochondrial pseudogenes (data not shown). The data were then used for the construction of a phylogenetic tree reported in Figure 5, that estimate the divergence between the several species. In our study results evident that the "Grotta del Maresciallo" species examined have genetic distance each other and tight cluster for all samples belonging to the class Actinopterygii, as for Arthropoda, Mollusca and Cnidaria Phyla. See e.g. in the three Mollusca Felimare picta, Discodoris atromaculata and Flabellina affinis that formed a close cluster, such as Porifera, with the Cnidaria Astroides calycularis and Parazoanthus axinellae, which exhibited similar close phylogenetic relationship between Agelas oroides, Petrosia ficiformis and Acanthella acuta. 
Citation: Madonna A, Alwany MA, Rabbito D, Trocchia S, Labar S, et al. (2015) Caves Biodiversity in the Marine Area of Riviera d'Ulisse Regional Park, Italy: Grotta del Maresciallo Overview. J Biodivers Endanger Species 3: $153 . \quad$ doi: $10.4172 / 2332-2543.1000153$

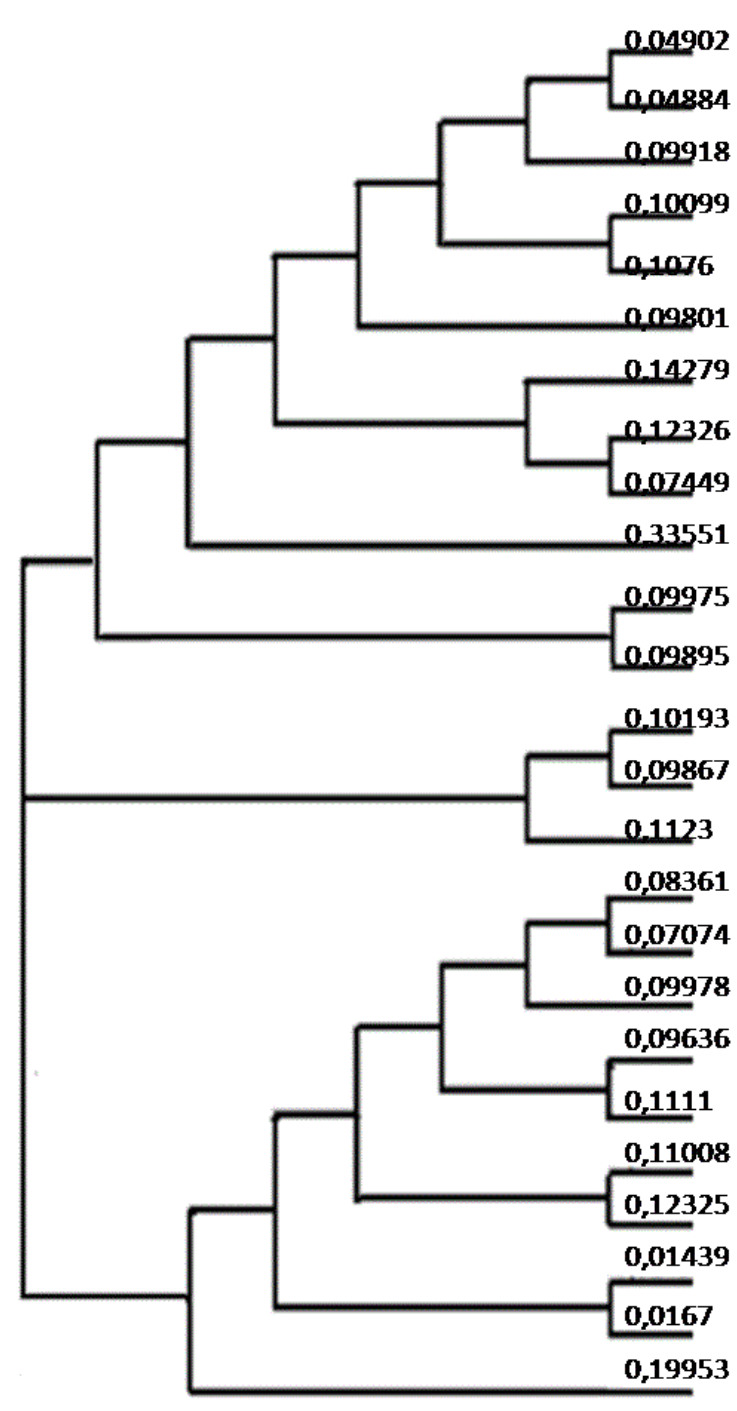

Epinephehus costae JX456389

Epinephelusmarginotus KC500692

Scorpaena notota $\mathrm{KJ768308}$

Muraena helena KJ768264

Phycisphycis KJ768279

Congerconger KJ709742

Paracentrotus fividus EF462949

Arbacia lixula JQ745256

Echinastersepositus GU330217

Scyllarusarctus KC789473

Lwio lurida AY161695

Stramonita haemastoma FR695839

Felimare picta LN715204

Discodoris atromaculota AF120637

Flabelina offinis H0616753

Acanthella acuta KC789473

Petrosia ficiformis JX999088

Agelas oroides JX999060

Astroides calycularis J0343192

Parazoanthusaxinellae EF672659

Chondrosia reniformis JX999074

Crambecrambe JX999091

Scalarispongia scalaris $J 0082796$

Spongia officinalis H0830364

Clavelina lepadiformis AY603104
CHORDATA

(Actinopteryeii)

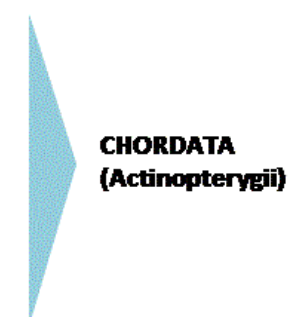

ARTHROPODA

Mowusca

PORIFERA

CNIDARIA

PORIFERA

CHORDATA

(Ascidiacea)
ECHINODERMATA

Figure 5: Neighbour Joining tree for partial sequences of the mitochondrial cytochrome oxidase subunit I (COI)gene of species from the "Grotta del Maresciallo" cave. Species names and GenBank accession numbers are given at branch tips. Numbers indicates genetic distances.

\section{Discussion}

During the course of the current biological studies, several significant geological data (depth, light and hydrodynamism) and Mediterranean comparative phenomena too have been recorded by scuba divers of our equipè for the cave examined named "Grotta del Maresciallo", one of the eight cave at Marine Area of Riviera di Ulisse in Italy. See, for example the component of the rocky bottoms that are carbonate rocks, as reported in other marine caves in many coastal marine areas of the Mediterranean environment for karstic processes [8] and submerged little stalactites and stalagmites, which are known to form only in air. The development of specialized cave diving techniques and equipment used has provided a mean to gain access to the submerged cave as our small cave examined. The visual census technique carried out was focus on the identification of marine cave species for their protection, according to the current Habitat Directive including the Marine Strategy Framework Directive and the Barcelona
Convention, the Intergovernmental Science-Policy Platform on Biodiversity and Ecosystem Services (IPBES) as the Intergovernmental Panel on Climate Change (IPCC) $[1,2,19]$. The used approach and methods have proved to be the most efficient to assess species abundance and diversity overview, because of their minimal impact. To get a better description of species diversity, a measure of diversity indices, species richness and evenness of their distribution at the entrance and inside the "Grotta del Maresciallo" cave were undertaken too. Examination of the fauna from the cave recorded 47 species. They belong to 46 families and 12 different classes and no one species is dominant but the Margalef index indicates that the number of species is very high compared to the specimens examined. The low evenness and the variation in richness between zone 1:semi-dark and zone 2: dark cave (Table 1) could reflect the not negligible variability among the investigated cave in terms e.g. of morphology, length and presence/ absence of light in the innermost portions. Indeed, the calculated taxa 
Citation: Madonna A, Alwany MA, Rabbito D, Trocchia S, Labar S, et al. (2015) Caves Biodiversity in the Marine Area of Riviera d'Ulisse Regional Park, Italy: Grotta del Maresciallo Overview. J Biodivers Endanger Species 3: $153 . \quad$ doi: 10.4172/2332-2543.1000153

Page 11 of 13

percentage contribution of the "Grotta del Maresciallo" biodiversity integrates the Mediterranean's evaluation already calculated and reported in literature [36], showing the taxa of "Grotta del Maresciallo" result to be copius for Chordata, Echinodermata, Arthropoda in relation to the biodiversity found in caves of the central Mediterranean sea (shown in green), and in general in all the caves of the Mediterranean [12]. The presence of abundant sponges (see Table 1) on overhanging ledges in these caves, but not observed elsewhere, indicates that even in deep waters, caves offer a preferred biological niche for some animals. Moreover, marine caves as the zone 1 and 2 of the "Grotta del Maresciallo" might be used for sponge culture, due to their limited sediment deposition and illumination [20]. Considering the importance to follow the biodiversity $[42,43]$, the limitation due to organism morphology for micro- and meiofauna that require the high expertise and costs $[23,24]$ and that differentiation of closely related species constitutes a challenging task not only for morphological, but genetic methods as well, the DNA barcoding studies are also included. In our study, a data set of 25 COI sequences from the "Grotta del Maresciallo" species was obtained and compared with ones already present in GenBank data. Our analyses indicate that the individuals examined, that were reliably assigned binomial names a priori, possessed distinct COI sequences. The use of molecular markers (such as COI) to identify cases of termophilic or alien invasions is a promising method that may resolve the status of some issues recorded in literature [26,27], especially thanks the genetic distance that can be present in cave's species, as in our case, where distinct clusters for vertebrate and invertebrate are evident. Our data confirmed the taxonomy of a widely distributed species, present in Marine Mediterranean cave e.g. the fish Apogon imberbis, the sponges Agelas oroides, Petrosia ficiformis, Chondrosia reniformis $[9,12]$ and permits to identify species with great interest for their edibility as the fishes, Scorpaena notate, Phycis phycis, Conger conger, Sciaena umbra, Epinephelus marginatus, Epinephelus costae; the mollusca, Stramonita haemastoma, Arca noae, the crustacea Scyllarus arctus, Palaemon serratus and Parapandalus narval. Furthermore, we detected in the "Grotta del Maresciallo" cave a lot of species with various economic utility: against human breast cancer (MCF-7) and human neuroblastoma (SH-SY5Y) cell lines as for the spiny starfish, Marthasterias glacialis [44]; potential unexploited collagen source, easily obtainable as a food industry waste product, as for the edible sea urchin Paracentrotus lividus [45]; source of original natural substances belonging to two families of guanidine alkaloids, namely crambescins and crambescidins, which exhibit cytotoxic and antiviral activities, as for the orange-red encrusting sponge, Crambe crambe [46] and natural source of nanoparticles for the transdermal drug delivery of 17beta-estradiol-hemihydrate in hormone replacement therapy, as for the kidney-shaped sponge, Chondrosia reniformis [47]. Furthermore, in the "Grotta del Maresciallo" can be found species where were isolated actinobacterial strains and screened for antagonistic activity against various bacterial and fungal pathogens, as for the bath sponge, Spongia officinalis [48] and were isolated and purified acetylcholinesterase inhibitor isolated, as from the yellow encrusting anemone, Parazoanthus axinellae [49]. Known are the biological activities of the bacterial community associated with the bluish encrusting sponge, Phorbas tenacior, the antimicrobial 2aminoimidazole alkaloid produced by the calcareous sponge, yellow network sponge, Clathrina clathrus, the antifungal effects of secondary metabolites isolated from the orange lumpy sponge, Achantella acuta; the effects of the orange lobed sponge, Agelas oroides and of the stony sponge Petrosia ficiformis crude extracts on human neuroblastoma cell survival; the tryptophan derivatives from the anthozoan, the star coral, Astroides calycularis. So, the combination of morphological and molecular data could be essential for accurately assessing the world's biodiversity indicating useful diagnostic morphological traits, informing needful revision, and flagging unseen species. Moreover, the BOLD system, which deposits barcodes, morphological, geographical and other data, has the potential as a convenient taxonomic platform [23] rapid, and accurate means of identifying specimens and assessing biodiversity and permitted to demonstrate the presence of two established thermophilic species, as Astroides calycularis and Epinephelus costae as the consequence of sea water temperature anomalies on a Mediterranean submarine cave ecosystem $[4,50]$; the tropical species Parablennius pilicornis, as biological pollution effect, the arrival already evidenced in the Mediterranean $[18,51]$ and by the authors also in the Gaeta Gulf [17]; the rare species, Grammonus ater, and some uncommon species such as Stenopus spinosus and Gnatophillum elegans and the endangered species Epinephelus marginatus, included in the IUCN Red List (http:// www.iucnredlist.org), encountered in several different marine caves review by [review in ref. 12,52,53] in the eastern Mediterranean. The use of DNA barcoding method is hindered by the fact that only a lowest percentage of the phyla have an associated barcode. So, for their richness, the caves can offer this opportunity to add new data in the panorama of mitochondrial sequence too (see our contribution at http://www.ncbi.nlm.nih.gov/genbank/, accession number KM606627, for Sciaena umbra; and KJ499110 for Conger conger from gametes and muscle specimens of the "Grotta del Maresciallo"). This first attempt to assess the state of knowledge on the submarine caves of Riviera di Ulisse marine area evidenced that the most important gap that should be filled in the near future concerns the biology and ecology of cavedwelling communities. A detailed and updated knowledge on the submarine caves would provide the basic information for protection measures, to strengthen the science-policy interface for biodiversity and ecosystem services for the conservation and sustainable use of biodiversity, long-term human well-being and sustainable development especially for those caves that today are still outside the boundaries of marine protected areas and of sites of community interest.

\section{Acknowledgment}

The authors thank the managers of the Park, Riviera di Ulisse and the School of Nautical "Guardia di Finanza "of Gaeta, LT (Italy) for granting the opportunity and logistic organization respectively to make a statement of geological structure and cataloging of species at "Grotta del Maresciallo". The research was supported by Federico II University, Naples, Italy.

\section{References}

1. Dux T (2011) The Regime for the Protection of Specific Areas of the EEZ for Environmental Reasons under International Law. In: Specially Protected Marine Areas in the Exclusive Economic Zone (EEZ). pp227-456.

2. Roberts J (2006) The application and Future development of the IMO's particularly sensitive sea area concept. In: Marine Environment protection and Biodiversity conservation. pp31-42.

3. Terlizzi A, Fraschetti S, Guidetti P, Boero F (2002) The effects of sewage discharge on shallow hard substrate sessile assemblages. Mar Pollut Bull 44: 544-550.

4. Parravicini V, Guidetti P, Morri C, Montefalcone M, Donato M, et al. (2010) Consequences of sea water temperature anomalies on a 
Citation: Madonna A, Alwany MA, Rabbito D, Trocchia S, Labar S, et al. (2015) Caves Biodiversity in the Marine Area of Riviera d'Ulisse Regional Park, Italy: Grotta del Maresciallo Overview. J Biodivers Endanger Species 3: $153 . \quad$ doi: $10.4172 / 2332-2543.1000153$

Page 12 of 13

Mediterranean submarine cave ecosystem. Estuarine Coastal and Shelf Science 86: 276-282.

5. Elliott M (2003) Biological pollutants and biological pollution--an increasing cause for concern. Mar Pollut Bull 46: 275-280.

6. Zenetos A, Akel EhKh, Apostolidis C, Bilecenoglu M, Bitar G, et al. (2015) New Mediterranean Biodiversity Records.Mediterranean Marine Science 16: 266-284.

7. Gerovasileiou V, Voultsiadou E, Issaris Y, Zenetos A (2015) Alien biodiversity in Mediterranean marine caves. Marine Ecology.

8. Anzidei M, Lambeck K, Antonioli F, Furlani S, Mastronuzzi G, et al. (2014) Coastal structure, sea-level changes and vertical motion of the land in the Mediterranean. In: Sedimentary Coastal Zones from High to Low Latitudes: Similarities and Differences. The Geological Society of London 388: 453-480.

9. Bussotti S, Guidetti P, Belmonte G (2003) Distribution patterns of the cardinal fish, Apogon imberbis, in shallow marine caves in southern Apulia. Italian Journal of Zoology 70: 153-157.

10. Zenetos A, Gofas S, Morri C, Rosso A, Violanti D, et al. (2012) Alien species in the Mediterranean Sea. A contribution to the application of European Union's Marine Strategy Framework Directive (MSFD). Introduction trends and pathways.Mediterranean Marine Science 13: 328-352.

11. Guerriero G, Di Finizio A, Ciarcia G (2010) Biological Pollution: Molecular Identification of Non-Native Species in the Central Tyrrhenian Sea. CATRINA 5: 41-47.

12. Gerovasileiou V, Chintiroglou CC, Vafidis D, Koutsoubas D, Sini M, et al. (2015) Census of biodiversity in marine caves of the eastern Mediterranean Sea. Mediterranean Marine Science 16: 245-265.

13. Alwany MA (2008) Specie diversity and quantitative distribution of the surgeon fishes (Family, Acanthuridae) along Aqaba Gulf, Red Sea, Egypt. Egyptian Journal of Aquatic Biology and Fisheries 12: 93-107.

14. Alwany MA (2008) Distribution, Abundance and Diversity of Wrasses (Family Labridae) Along Sharm El-Sheikh Coast, Red Sea. CATRINA 3: 75-82.

15. Fernandez Alvarez FA, Machordom A (2013) DNA barcoding reveals a cryptic nemertean invasion in Atlantic and Mediterranean waters. Helgoland Marine Research 67: 599-605.

16. De Astarloa JMD, Mabragaña E, Hanner R, Figueroa DE (2008) Morphological and molecular evidence for a new species of longnose skate (Rajiformes: Rajidae: Dipturus) from Argentinean waters based on DNA barcoding. Zootaxa 1921: 35-46.

17. Guerriero G, Trocchia S, Rabbito D, Petrella M, Gallo A, et al. (2014) Barcoding of the Central Tyrrhenian fish species (Gaeta Gulf). Biologia Marina Mediterranea 21: 121-122.

18. Bilecenoglu M, Alfaya JEF, Azzurro E, Baldacconi R, Boyaci YÖ, et al. (2013) New Mediterranean Marine biodiversity records. Mediterranean Marine Science 14: 463-480

19. Giakoumi S, Sini M, Gerovasileiou V, Mazor T, Beher J, et al. (2013) Ecoregion-based conservation planning in the Mediterranean: dealing with large-scale heterogeneity. PLoS One 8: 76449.

20. Gerovasileiou V, Voultsiadou E (2012) Marine caves of the Mediterranean Sea: a sponge biodiversity reservoir within a biodiversity hotspot. PLoS One 7: 39873 .

21. Clavero M, García-Berthou E (2005) Invasive species are a leading cause of animal extinctions. Trends Ecol Evol 20: 110.

22. Darling JA, Blum MJ (2007) DNA-based methods for monitoring invasive species: a review and prospectus. Biological Invasions 9: 751-765.

23. Chen J, Li Q, Kong L, Yu H (2011) How DNA barcodes complement taxonomy and explore species diversity: the case study of a poorly understood marine fauna. PLoS One 6: e21326.

24. Tahseen Q (2014) Taxonomy-The Crucial yet Misunderstood and Disregarded Tool for Studying Biodiversity. Journal of Biodiversity \& Endangered Species 2:128.

25. Polidoro BA, Livingstone SR, Carpenter KE, Hutchinson B, Mast RB, et al. (2009) Status of the World's Marine Species. In: Wildlife in
Changing World - An Analysis of the 2008 IUCN Red List of Threatened Species. Gland, Switzerland: IUCN.

26. Hebert PD, Cywinska A, Ball SL, deWaard JR (2003) Biological identifications through DNA barcodes. Proc Biol Sci 270: 313-321.

27. Hebert PDN, Ratnasingham S, deWaard JR (2003) Barcoding animal life: cytochrome $\mathrm{c}$ oxidase subunit 1 divergences among closely related species. Proceedings of the Royal Society Biological Science 270: 96-99.

28. Folmer O, Black M, Hoeh W, Lutz R, Vrijenhoek R (1994) DNA primers for amplification of mitochondrial cytochrome c oxidase subunit I from diverse metazoan invertebrates. Mol Mar Biol Biotechnol 3: 294-299.

29. Pérès JM and Picard J (1964) Noveau manuel de bionomie benthique de la Mer Mediterranée. Recueildes Travaux de la Station Marine d'Endoume 31: 1-37.

30. Hooper JNA, van Soest RWM (2002) Systema Porifera. A guide to the classification of sponges. New York: Kluwer Academic/Plenum Publishers.

31. van Soest RWM, Boury-Esnault N, Hooper JNA, Rützler K, de Voogd NJ, et al. (2012) World Porifera database.

32. Costello MJ, Bouchet P, Boxshall G, Fauchald K, Gordon D, et al. (2013) Global coordination and standardisation in marine biodiversity through the World Register of Marine Species (WoRMS) and related databases. PLoS One 8: e51629.

33. Chimenz Gusso C, Nicoletti L, Bondanese C (2014) Briozoi Biologia Marina Mediterranea 20: p330.

34. Pielou EC (1966) Shannon's formula as a measure of specific diversity. Its use and misuse. American Naturalist 100: 463-465.

35. Loya Y (1972) Community structure and species diversity of hermatypic corals at Eilat, Red Sea. Marine Biology 13: 100-123.

36. Gerovasileiou V, Voultsiadou E (2014) Mediterranean marine caves as biodiversity reservoirs: a preliminary overview. In: Symposia on the conservation of Mediterranean marine key habitats. Portorož : 27-31.

37. Di Finizio A, Guerriero G, Russo GL, Ciarcia G (2007) Identification of gadoid species (Pisces, Gadidae) by sequencing and PCR-RFLP analysis of mitochondrial $12 \mathrm{~S}$ and $16 \mathrm{~S}$ rRNA gene fragments. European Food Research and Technology 225: 337-344.

38. Ward RD, Zemlak TS, Innes BH, Last PR, Hebert PD (2005) DNA barcoding Australia's fish species. Philos Trans R Soc Lond B Biol Sci 360: 1847-1857.

39. Thompson JG, Higgins DG, Gibson TJ (1994) CLUSTAL W: improving the sensitivity of progressive multiple sequence alignments through sequence weighting, position specific gap penalties and weight matrix choice. Nucleic Acids Research 22: 4673-4680.

40. Hall TA (1999) BioEdit: a user-friendly biological sequence alignment editor and analysis program for Windows 95/98/NT. Nucleic Acids Symposium Series 41: 95-98.

41. Kumar S, Tamura K, Nei M (2004) MEGA3: Integrated software for Molecular Evolutionary Genetics Analysis and sequence alignment. Brief Bioinform 5: 150-163.

42. Patel DK (2014) Biodiversity and its loss. Journal of Biodiversity and Endangered Species 2: 114

43. Patel DK (2014) Biodiversity and its Importance. Journal of Biodiversity and Endangered Species 2: 117.

44. Pereira DM, Correia-da-Silva G, Valentão P, Teixeira N, Andrade PB (2013) Palmitic acid and ergosta-7,22-dien-3-ol contribute to the apoptotic effect and cell cycle arrest of an extract from Marthasterias glacialis L. in neuroblastoma cells. Mar Drugs 12: 54-68.

45. Benedetto CD, Barbaglio A, Martinello T, Alongi V, Fassini D, et al (2014) Production, characterization and biocompatibility of marine collagen matrices from an alternative and sustainable source: the sea urchin Paracentrotus lividus. Mar Drugs 12: 4912-4933.

46. Pérez-López P, Ternon E, González-García S, Genta-Jouve G, Feijoo G, et al. (2014) Environmental solutions for the sustainable production of bioactive natural products from the marine sponge Crambe crambe. Sci Total Environ 475: 71-82. 
Citation: Madonna A, Alwany MA, Rabbito D, Trocchia S, Labar S, et al. (2015) Caves Biodiversity in the Marine Area of Riviera d'Ulisse Regional Park, Italy: Grotta del Maresciallo Overview. J Biodivers Endanger Species 3: $153 . \quad$ doi: $10.4172 / 2332-2543.1000153$

Page 13 of 13

47. Nicklas M, Schatton W, Heinemann S, Hanke T, Kreuter J (2009) Preparation and characterization of marine sponge collagen nanoparticles and employment for the transdermal delivery of 17betaestradiol-hemihydrate. Drug Dev Ind Pharm 35: 1035-1042.

48. Sathiyanarayanan G, Gandhimathi R, Sabarathnam B, Seghal Kiran G, Selvin J (2014) Optimization and production of pyrrolidone antimicrobial agent from marine sponge-associated Streptomyces sp. MAPS15. Bioprocess Biosyst Eng 37: 561-573.

49. Strupi Suput J, Turk T, Macek P, Suput D (1996) Pseudozoanthoxantinlike compound from Parazoanthus axinellae Adriaticus inhibits acetylcholinesterase. Pflugers Archiv 431: 315-316.
50. Hui D (2013) Global Climate Change and Biodiversity: Issues and Future Research. Journal of Biodiversity and Endangered Species 1: 105.

51. Guerriero G (2013) Non-Native Species and Biodiversity Assessment. Journal of Biodiversity and Endangered Species 1: 104.

52. Campbell M (2012) Biodiversity and Endangered Species: Issues of Significance. Journal of Biodiversity and Endangered Species 1: 102.

53. Heibult Sawchuk J, Beaudreau AH, Tonnes D, Fluharty D (2015) Using stakeholder engagement to inform endangered species management and improve conservation. Marine Policy 54: 98-107. 